\title{
O corpo feminino em discurso: memória e (r)existência
}

DOI: http://dx.doi.org/10.21165/el.v49i2.2477

\section{Marco Antonio Almeida Ruiz'}

\section{Resumo}

O corpo feminino traz certas memórias de violência no interior da história construídas e reverberadas pelas práticas sociais que se materializa(ra)m nos e pelos discursos. Tal condição possibilitou um certo idealismo do seu corpo, visto como objeto sexual, além de colocá-lo num espaço discursivo de luta, sempre desigual. A partir de certos movimentos sociais em prol das mulheres, podemos dizer que há a instauração de uma nova memória ressignificada pelo corpo que resiste, que produz dizeres e que movem as mulheres na luta contra certos imaginários socialmente estigmatizados. Vemos, a partir dessas novas condições de produção a passagem do corpo terno e delicado de antigamente ao corpo profano, dono de si, militante. Embasados teórico-metodologicamente na análise do discurso francesa, nosso objetivo, com este artigo, é analisar essa nova memória que emerge a partir do surgimento de movimentos sociais feministas, tais como, a Marcha das Vadias e a Marcha das Margaridas. Nosso material é composto por alguns recortes de páginas feministas do Facebook e da mídia.

Palavras-chave: corpo feminino; discurso; memória; resistência.

1 Universidade de São Paulo (USP), São Paulo, São Paulo, Brasil;

marcoalmeidaruiz@gmail.com; https://orcid.org/0000-0003-2438-9252 


\title{
The female body in discourse: memory and (r)existence
}

\begin{abstract}
The female body brings memories of violence within history built and reverberated by social practices that materialize in and by discourses. This condition made possible a certain idealism of the body, seen as a sexual object, besides placing it in a discursive space of struggle, always unequal. From certain social movements in favor of women, we can say that there is the establishment of a new memory resignified by the body that resists, which produces words that move women in the fight against certain socially stigmatized imaginary. We see, from these new conditions of production, the transition from the formerly tender and delicate body to the profane body, owner of itself, militant. Theoretically and methodologically based on the french discourse analysis, in this article our objective is to analyze this new memory that emerges from the rise of feminist social movements, such as the Marcha das Vadias and Marcha das Margaridas (in Portuguese). Our corpus consists of some clippings from feminist pages from Facebook and the media in general.
\end{abstract}

Keywords: female body; discourse; memory; resistance.

\section{Introdução}

Durante muito tempo, as mulheres foram alvo de discursos que as rebaixavam diante dos homens por serem consideradas "delicadas". Sua condição feminina - idealizada -, de ser mulher, era uma das razões para afastá-las de muitas das atividades sociais, colocando-as em um espaço pré-determinado, da ordem do privado, dona de casa ${ }^{2}$, esposa dedicada e cuidadora dos filhos, ao contrário dos homens, responsáveis por ocupar o espaço público e possuir a destreza nos negócios. O corpo feminino, diante

\footnotetext{
2 Em 2016, por exemplo, numa reportagem da revista Veja, intitulada "Marcela Temer: bela, recatada e 'do lar"' (LINHARES, 2016), observamos a cristalização de um imaginário preconceituoso sobre as mulheres, em que mesmo diante de toda a sua resistência e luta conquistada na história, ainda são idealizadas e nomeadas por certos rótulos sociais, tais como: dona de casa, "do lar", bela, recatada, entre outros. A reportagem destacava as qualidades para ser uma "boa esposa", ou seja, é aquela que ocupa o espaço da casa, cuida dos afazeres domésticos e dos filhos e auxilia o marido, um homem de negócios e responsável pelo sustento. Nas palavras da revista, "Michel Temer é um homem de sorte", pois teria ao lado dele uma mulher "ideal", já que a senhora Temer, ex-primeira-dama, possuía tais características elencadas. Metonimicamente, a mulher idealizada da reportagem configura um imaginário ainda fortemente estigmatizado na sociedade contemporânea, em que ela é (ex)posta como objeto de desejo, da ordem do sagrado, fruto da perfeição e moldada em certos padrões, desconsiderando, assim, toda a sua militância e direitos já conquistados em busca da igualdade. Disponível em: https://veja.abril.com.br/brasil/marcelatemer-bela-recatada-e-do-lar/. Acesso em: 6 maio 2020.
} 
desse cenário preconceituoso, e enquanto objeto do desejo, foi um dos lugares em que mais se representou essa prática de exclusão, de violência contra a mulher, nos diferentes níveis (físico, emocional e psicológico). Nesse sentido, podemos dizer que seu corpo traz memórias de violência no interior da história construídas e reverberadas pelas práticas sociais que se materializa(ra)m nos e pelos discursos. Tal condição possibilitou certos idealismos do corpo feminino, colocando-o, por exemplo, como reflexo de uma beleza padronizada socialmente, pré-construída e de segregação (corpo magro, cabelos longos e lisos), assim como do pudor e como objeto sexual, associando-o, muitas vezes, aos prazeres da carne, logo, coloca-o violentamente num espaço discursivo de luta, sempre desigual. Assim, as mulheres e seus corpos são atingidos pela violência física, emocional e psicológica que são frutos da história e das memórias criadas em discurso.

Para este artigo temos como objetivo traçar um breve esboço da história do feminismo e das lutas de mulheres diante de uma sociedade fortemente machista por meio dos movimentos sociais. Apesar da luta e da militância, é preciso ainda ratificar o direito das mulheres e a sua igualdade em todas as esferas da sociedade perante discursos misóginos $^{3}$ e autoritários. Ademais, observamos como o corpo feminino adquire novos sentidos e ressignificações no ciberespaço como forma de (r)existência. Para tal, analisamos um conjunto de imagens divulgadas pela mídia, postagens de páginas feministas da rede social Facebook que reverberam a luta constante das mulheres em relação aos preconceitos e desigualdades. Nossas reflexões inscrevem-se na análise do discurso de matriz francesa, em especial empreendendo as noções de memória (PÊCHEUX, 2010) e de condições de produção (PÊCHEUX, 2014; PÊCHEUX; FUCHS, 2014), esta última a partir da visada teórica promovida pela linguista brasileira Eni Orlandi (2002). Observamos, nesses materiais, a ressignificação da memória de violência retratada no/do corpo a partir de certos movimentos sociais brasileiros - Marcha das Vadias (2013) e Marcha das Margaridas (2019) -, em que por meio de escritas sob a sua pele e as exposições dos seus corpos, as mulheres entoam um grito de (r)existência diante de todo o preconceito e segregação.

3 Em agosto de 2019, em tom de deboche e preconceituoso, Bolsonaro respondeu a um comentário de um seguidor numa rede social em que comparava as imagens sua e de sua esposa, Michelle Bolsonaro, com as de Emmanuel Macron e Brigitte Macron, presidente e primeira dama da França. O comentário do seguidor foi o seguinte: "Agora entende porque Macron persegue Bolsonaro", fazendo referência direta à Michelle Bolsonaro e Brigitte Macron, insinuando que, por ser 29 anos mais velha, a esposa do presidente francês era feia. Tal insinuação misógina se corrobora com o comentário do presidente brasileiro "não humilha cara. Kkkkkkk". Esse caso infeliz, mais uma vez, ratifica um imaginário preconceituoso e destaca a violência contra as mulheres e seus corpos, cujo imaginário é mensurado por certos padrões - de beleza, sobretudo - cristalizados na história pelas sociedades. Disponível em: https://veja.abril.com.br/mundo/bolsonaro-zomba-da-esposade-macron-e-e-acusado-de-sexismo/. Acesso em: 6 maio 2020. 


\section{Retornando à história: um breve percurso do feminismo no Brasil}

Na história, a mulher sempre foi (e ainda é!) alvo de discursivização, em especial o seu corpo sempre foi tornado em discurso. Nas artes, o corpo feminino é reconhecido como um objeto de desejo, do olhar erotizado, mas sempre calado devido ao pudor e à feminilidade. Dante Alighieri, Rafael e outros pintores do Renascimento, por exemplo, em suas obras faziam alusão às mulheres como deusas gregas e romanas. Já no campo da literatura, as obras de Saramago $(2001,2005,2006)$ ressaltam a mulher por meio de capacidades extraordinárias, em Memórias de um sargento de milícias (1991), de Manuel Antonio de Almeida e Tieta do Agreste (1977), de Jorge Amado, o feminino é exaltado e os autores destacam em suas histórias o papel da mulher e a sua influência sobre o homem por meio de um suposto poder de sedução. Na mídia, por sua vez, encontramos distintos dizeres sobre a mulher e, em especial, o seu papel em distintas temáticas, como de políticas, de beleza, de moda, em que todos os sentidos gerados são (re)produzidos a partir de uma rede de filiações ideológicas. Assim, a mulher, nessa rede discursiva, assumiria o ônus e o bônus justamente por ocupar esse espaço de polêmica.

Para este nosso caminho de reflexão, o corpo não é apenas o de carne, mas construído em discurso pelas práticas sociais que assumem sentidos na história e ratificam certos imaginários cristalizados em relação à mulher e ao seu lugar de fala no interior de certas ideologias dominantes e preconceituosas. Em virtude disso, buscamos analisar a formulação, a constituição e a circulação (ORLANDI, 2002) desse discurso de militância (re)produzido pelo corpo e suas inscrições no ciberespaço, que ratifica a sua (r)existência a essas formações dominantes.

Entretanto, para compreender essa relação do digital e a militância de mulheres em movimentos sociais na contemporaneidade, é necessário retomarmos um pouco da história do movimento de mulheres que lutaram bravamente em busca de seus direitos, o chamado movimento feminista. Vejamos:

O feminismo tem provocado militâncias apaixonadas e raivas incontidas. Desde suas primeiras manifestações, ainda no século XIX o movimento foi muito particular, pois desafiou ao mesmo tempo a ordem conservadora que excluía a mulher do mundo público - portanto, dos direitos como cidadão - e também as propostas revolucionárias, que viam na luta das mulheres um desvio de pugna do proletariado por sua libertação. (PINTO, 2003, p. 9) 4 .

4 Céli Regina Jardim Pinto é autora de uma das principais obras sobre o feminismo no Brasil, Uma história do feminismo no Brasil (2003). Seu livro é organizado em quatro capítulos e tem como mote informações coletadas das escritoras feministas Albertina Costa, Anette Goldberg, Mary Castro, Moema Toscano, Mirian Goldberg, Mirian Grossi, Miriam Moreira Leite, Schuma Shumaher, Sonia Álvares e Vera Soares. A autora, durante a sua exposição, ressalta os múltiplos objetivos e manifestações do feminismo no país; conforme suas palavras, trata-se de um movimento difuso 
Em seu livro Uma história do feminismo no Brasil (2003, p. 9), Pinto assevera que não é fácil descrever a história desse movimento, pois "se trata de um fenômeno que ainda vivemos de forma muito presente e sobre o qual ninguém, homens ou mulheres, nas últimas décadas, ficou imune a ter uma opinião". Conforme o autor, o início do século XX tornase um importante cenário de movimentos de mulheres que ganhavam corpo, em que buscavam uma maior articulação e participação nas decisões do país, uma conquista alcançada apenas nos anos de 1932 por meio do direito ao voto. O corpo silenciado começa a ganhar contornos de liberdade, a exaltar, assim, uma condição de igualdade. 1975 tornou-se um ano de grande marco histórico para as mulheres do Brasil, pois além de a ONU defini-lo como o ano internacional da Mulher, permitiu a criação do Centro de Desenvolvimento da Mulher Brasileira. Trata-se de um centro criado no Rio de Janeiro a partir de um grupo de mulheres que propuseram comemorar essa data, assim como possibilitou tornar-se públicos e institucionalizados os movimentos feministas (PINTO, 2003).

Nos anos oitenta, muitas das mulheres que estavam exiladas na Europa e nos Estados Unidos voltaram ao nosso país com um novo espírito de força. Tratou-se de uma nova forma de ressignificar a condição feminina pregnante historicamente - como, por exemplo, rainha do lar, dona de casa, recatada - e instituir uma nova memória social, a de resistência. A violência contra a mulher, nessa época, tornou-se tema oficial pela primeira vez e foi discutido publicamente. Tais discussões, em meados de 1984, foram oficialmente destacadas pela ratificação do governo brasileiro da Convenção para Eliminar Todas as Formas de Discriminação contra a Mulher (CEDAW).

Em 1985, temos a primeira delegacia da mulher e do Conselho Nacional dos Direitos da Mulher. Ainda nessa caminhada de militância e (r)existência, em 1994, o Brasil, no combate à violência contra o feminino, apoiou a Convenção Interamericana para Prevenir, Punir e Erradicar a Violência contra as Mulheres. Esse conjunto de dispositivos sociais criados assumem, de certo modo, uma dupla função: de um lado, a necessidade de rememorar a violência que as mulheres sofreram, refletindo e refratando no/em discurso as memórias que lembram a historicidade da violência no corpo feminino e, de outro, a instauração de uma nova memória, a de luta, resistência e militância, de um corpo que sofreu (e ainda sofre) violentamente. Nesse momento, tal corpo e sua feminilidade não são motivos para continuar a mantê-los "privados", pelo contrário, são corpos em discursos que falam de uma nova realidade social. O silêncio corporal que as mulheres se submeteram na história adquire novos contornos, em que não são os homens que reescrevem a história, mas sim as mulheres livres, cujo poder de participação social refere-se à total igualdade de direitos entre os gêneros.

que caracteriza duas tendências, a primeira, datada do final do século XIX até 1932 e a segunda marcada pelo período pós-1968. Cf.: OTTO, C. O Feminismo no Brasil: suas múltiplas faces. Revista Estudos Feministas, Florianópolis, v. 12, n. 2, p. 237-253, maio/ago. 2004. 
O ano de 2003 é considerado o momento de institucionalização e reconhecimento de movimentos sociais de mulheres a partir da criação, em âmbito ministerial, da Secretaria Especial de Políticas para as Mulheres, assim como o desenvolvimento de políticas públicas voltadas à mulher. Assim, neste artigo, buscamos analisar a memória de atualização do papel feminino na contemporaneidade, mediante as novas transformações sociais e a história de violência sofrida e ressignificada no/do corpo como discurso de resistência no digital. Ou seja, por meio da formulação de enunciados no/do corpo que rompem com a constituição de imaginários sociais cristalizados e fazem circular novas instâncias de discurso ressignificando formações discursivas dominadas é que podemos observar a instauração de uma nova memória graças aos movimentos e representações femininas que lutam para mudar certos imaginários preconceituosos. A internet, como um meio de circulação, possibilita a militância digital que se confıgura como um espaço do dizer, o corpo, antes silenciado, fonte de um desejo carnal, enaltecido nas artes, literaturas, por exemplo, adquire voz refletindo novas práticas sociais feministas em prol da igualdade de gêneros. Esse material digital instaura, assim, uma nova história de significação e luta de mulheres, ampliando a resistência aos diversos setores da sociedade, o ciberfeminismo. Nesse caminho de investigação, as mulheres usam o seu corpo, o de carne, para expressar a sua (r)existência em discurso, por meio de inscrições, enunciados que corroboram transformações de certas práticas sociais. Trata-se, pois, da instauração de uma memória de militância que ratifica a busca pela liberdade e igualdade feminina.

Ao longo da história, a (r)existência feminina foi marcada por inúmeros movimentos que anunciavam a transformação da mulher das artes, da literatura, por exemplo (como uma mulher idealizada, dona de casa, musa) para a mulher militante, trabalhadora. É nessa mudança, empreendida sobretudo pelas mulheres, que se ressignifica a memória. Assim, do corpo terno e delicado ao corpo profano, a nova memória está estampada em seu corpo e fala em discurso no ciberespaço. É essa memória um objeto caro aos analistas do discurso de orientação francesa. Mais especificamente, é nos trabalhos de Pêcheux (2010) acerca do Papel da memória, um conjunto de reflexões apresentadas durante o colóquio História e Linguística em 1983, que o autor questiona o modo como os efeitos de sentidos são gerados, despregando-se de uma visão conteudista vigente nos estudos de língua(gem) da época e proporcionando uma nova perspectiva discursiva de trabalho. Segundo Maldidier (1984), Pêcheux tornou-se um operário incansável promovendo caminhos que subverteram um certo domínio já determinado.

Assim, em Papel da memória, Pêcheux (2010, p. 50) afırma que a memória não deve ser interpretada no sentido psicologista enquanto uma "memória individual", mas por meio de sentidos "entrecruzados da memória mítica, da memória social inscrita em práticas, e da memória construída do historiador". Trata-se, pois, de inscrever um certo acontecimento num espaço da memória a partir de certas condições de produção de discursos. Nesse sentido, podemos dizer que alguns discursos tornam-se operadores de memória social, pois corroboram uma memória coletiva da historicidade da violência que as mulheres sofreram ao longo dos séculos e que, a partir desses novos fatos, novos acontecimentos, essa memória é ressignificada: 
Essa negociação entre o choque de um acontecimento histórico singular e o dispositivo complexo de uma memória poderia bem, com efeito, colocar em jogo a nível crucial uma passagem do visível ao nomeado, na qual a imagem seria um operador de memória social, comportando no interior dela mesma um programa de leitura, um percurso escrito discursivamente em outro lugar. (PÊCHEUX, 2010, p. 51).

A noção de condições de produção, cunhada por Pêcheux (2014a, 2014b), é um dos conceitos basilares da análise do discurso, em que vemos constantemente o jogo de forças e relações constituintes resultantes do processo discursivo. Em sua releitura, num contexto discursivo brasileiro, Orlandi (2002) compreende tal noção a partir de três níveis: a constituição, a formulação e a circulação. Dessa tríade, podemos pensar na produção de discursos sobre a militância feminina inscrita no corpo da mulher por meio dos dizeres que reatualizam uma memória de submissão, de violência e de preconceito em uma memória de (r)existência. Assim, conforme a autora, a constituição do dizer é estabelecida por meio de uma memória do dizer no qual se marcam discursivamente os efeitos de sentidos relativamente estabilizados, advindos de pré-construídos e discursos outros, já-ditos; em relação à formulação, ela efetivamente acontece a partir do momento em que as condições de produção desses dizeres se ligam, direta ou indiretamente, às circunstâncias da enunciação. Todavia, a transformação da memória acontece apenas no nível da circulação, pois há uma atualização, fazendo intervir os sujeitos e o jogo de sentidos como resultado da ressignificação de uma atualidade e uma memória baseados nas condições de emergência de discursos que refletem e refratam cada tempo e cada formação social. Orlandi (2002, p. 33) ressalta a importância desses três níveis discursivos como um processo, em que

A constituição determina a formulação, pois só podemos dizer (formular) se nos colocamos na perspectiva do dizível (interdiscurso, memória). Todo dizer, na realidade, se encontra na confluência dos dois eixos: o da memória (constituição) e o da atualidade (formulação). É desse jogo que tiram seus sentidos.

Assim, a memória social cristalizada, da mulher privada e dona de casa, é abandonada e com os movimentos sociais, o (ciber)feminismo instaura-se em uma nova história e memória de luta por meio da circulação de novos discursos que desmistifiquem, de certo modo, esse idealismo feminino atrelado historicamente à mulher. $\mathrm{O}$ espaço digital tem ocupado um lugar de fala e discurso importante na resistência das mulheres pela luta de seus direitos, adquirindo grandes proporções de circulação e adesão de mulheres em todo o mundo.

Em 2013, durante o movimento social Marcha das Vadias, vimos mulheres de todo o Brasil irem às ruas, entoarem a voz da resistência diante de um imaginário machista ainda muito forte e persistente. Esse movimento, que irrompeu a partir da necessidade 
de ratificar o papel da mulher perante discursos e formações discursivas dominantes de políticos autoritários, ressignificou sobretudo os seus corpos que se tornaram fonte de discurso ${ }^{5}$. O corpo feminino passou a expressar toda a luta, a resistência e a militância como discurso. Por isso, víamos corpos pintados, nus, que resistiam, que quebravam o silêncio e ressignificavam a memória e a história da violência sofrida durante muito tempo. Do corpo delicado, das artes, vemos, agora, um corpo que discursiviza, que milita a favor das mulheres e da igualdade, um verdadeiro porta-voz da (r)existência. Vadia, um termo que há muito tempo é associado às mulheres "da vida", adquiriu um novo sentido, não dicionarizado, uma nova memória graças aos movimentos sociais de resistência; assumiu, com isso, o valor de uma mulher valente, forte, que resiste a qualquer forma de violência e intolerância: "se lutar por igualdade é ser vadia, então eu sou vadia", conforme podemos observar em um dos enunciados de nosso corpus analítico. Em 2019, vimos, também, a Marcha das Margaridas, flores da resistência, um movimento social feminino que luta pela representatividade das mulheres e a defesa de seus direitos no campo, nas terras indígenas, por exemplo. A resistência se mostra crescente e fonte de novas instâncias do dizer que configuram uma nova era na história do feminino e, como consequência, uma nova memória: (r)existência.

Veremos a seguir como ocorre a instauração dessa nova memória de (r)existência no ciberespaço em que o corpo feminino fala, produz discursos em prol da liberdade e igualdade de gêneros e contra formações discursivas (FD) autoritárias e dominantes que assolam o nosso país. Como formações discursivas, a compreendemos como Pêcheux e Fuchs definiram em 2014 [1975] (p. 11):

[As formações discursivas] comportam, necessariamente, como um de seus componentes, uma ou várias formações discursivas interligadas que determinam o que pode e deve ser dito (articulado sob a forma de uma arenga, de um sermão, de um panfleto, de um relatório, de um programa, etc.), a partir de uma dada posição em uma conjuntura, em outras palavras, em uma certa relação de lugares interna a um aparelho ideológico e inscrita em uma relação de classes. Diremos assim que toda formação discursiva diz respeito a condições de produção específicas, identificáveis a partir do que acabamos de designar.

Nesse caminho, diante do desafio de resistir às formações discursivas dominantes, observamos o modo como as FDs dominadas criam estratégias discursivas inscritas no/do corpo que dão voz à sua (r)existência, que saem às ruas contra o preconceito e

5 Vemos em Azevedo (2014) uma contribuição sugestiva sobre o estudo do corpo na análise de discurso; seu objetivo foi, também, analisar a constituição do corpo em discurso. Segundo ela, "as imagens do corpo que se produzem e circulam na Web, em sua forma sobredeterminada pela mídia, passam a compor um universo de evidências de sentidos que naturalizam certas significações para os corpos dos sujeitos, a partir das formações ideológicas" (AZEVEDO, 2014, p. 322). 
instauram novas ressignficações. Por meio de alguns recortes do digital, entre figuras e postagens de perfis feministas nas redes sociais, como o Facebook, analisamos essa ressignificação da memória de violência instada pelos movimentos (ciber)feministas, ratificando uma história de luta, uma nova memória.

\section{(Ciber)feminismo e discurso: a memória de (r)existência na mídia e em perfis de redes sociais}

Na história da luta feminina, o seu corpo sempre foi alvo de diferentes discursos. Ele é ao mesmo tempo o objeto e o próprio discurso que não se calam. Nas atuais condições de produção que possibilitam a emergência de discursos machistas, misóginos e preconceituosos, o corpo assume o papel de ferramenta discursiva numa prática social de luta. A privação da mulher no ambiente familiar, os abusos e a violação de direitos tornaram-se uma violência diante de um corpo considerado há muito tempo sinônimo de subordinação. Essa mesma violência psicológica, abusiva, é, pois, ressignificada na contemporaneidade por meio da luta pelos direitos, dos corpos que podem e devem ser exibidos da maneira como as mulheres acharem conveniente, a forma de mostrarem a sua liberdade é exibindo os seus corpos de maneira que essa violência não seja esquecida no interdiscurso, mas rememorada de uma outra forma, por meio da resistência aos valores considerados tradicionais e obsoletos.

Temos, a partir dessas novas instâncias discursivas promovidas pela circulação da (r)existência no ciberespaço, imagens do corpo em discurso que promovem uma nova configuração de memória na história de militância feminina. A memória do corpo privado, recluso e o pudor que representa tal feminilidade se ressignifica do imaginário a partir de uma nova emergência de memória, de resistência, dos movimentos sociais de mulheres que usam o seu próprio corpo como fonte do dizer, como forma de expressar uma violência histórica e marcada na sociedade. No Brasil, por exemplo, observamos em algumas campanhas e/ou imagens divulgadas de mulheres que utilizam seus corpos como forma de resistência. Diante de um conjunto de ideais autoritários e retrógrados, o corpo terno assume a materialização do discurso militante, aquele que há muito tempo sofreu calado no interior da história e, a partir de agora, de uma nova situação de discurso, por meio dos movimentos sociais - Marcha das Vadias (2013), ${ }^{6}$ Marcha das Margaridas (2019), por

\footnotetext{
6 Garcia (2019), em uma interessante análise sobre esse movimento, destaca a campanha "meu feminismo é..." vinculada pela Marcha de Ouro Preto (2013), que era um convite a todas as mulheres a se manifestarem complementando tal frase com palavras que as definissem na atualidade, problematizando certos estereótipos e certas imagens pré-determinadas acerca de uma ideologia dominante; tal ação buscava promover um ideal de liberdade, de resistência e de luta das mulheres. Enquanto o corpo era tido pela sociedade como um objeto (de prazer, de violência, por exemplo), a autora vai mostrar que a Marcha das Vadias o toma como um instrumento de poder. Assim, podemos dizer que se trata de uma atualização da memória, uma ruptura da história que permite a redefinição do feminismo por meio da textualização no/do corpo.
} 
exemplo - há uma ressignificação do seu lugar de fala, o que faz o corpo militar, ser a fonte de discursivização contra todo o preconceito. Vejamos a seguir:

Figura 1. Marcha das Vadias

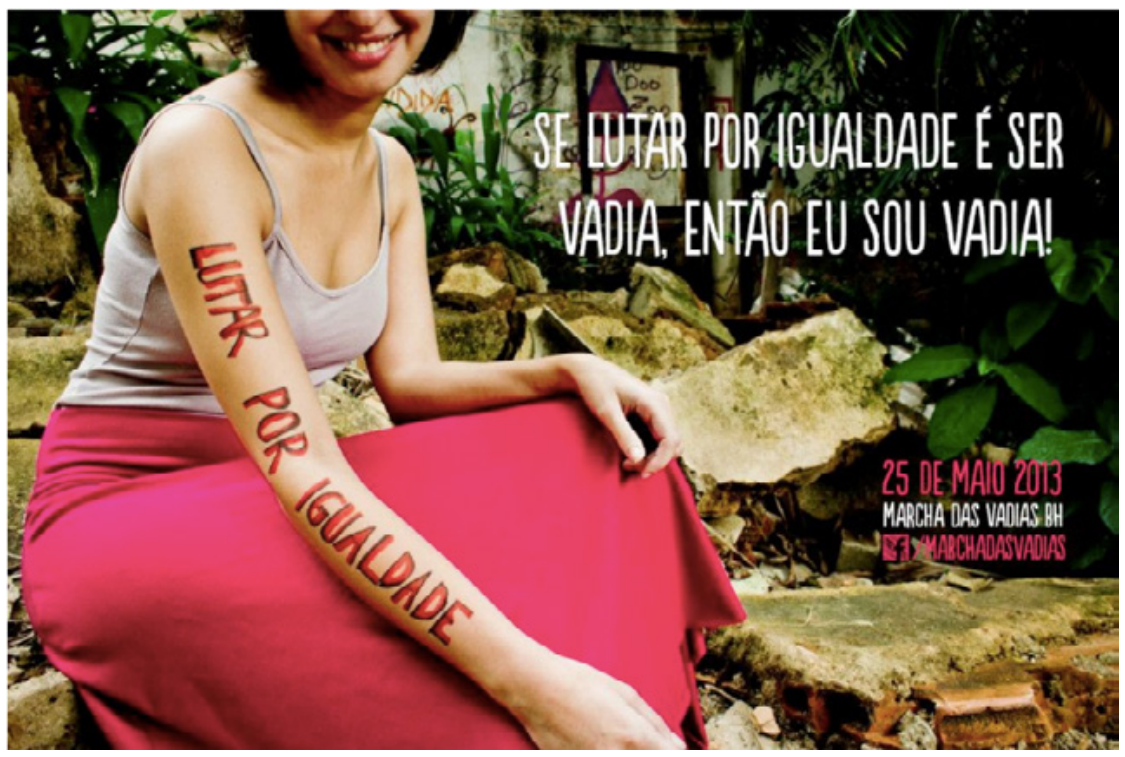

Fonte: https://bit.ly/3c8LJdg. Acesso em: 20 ago. 2019.

Figura 2. Marcha das Vadias

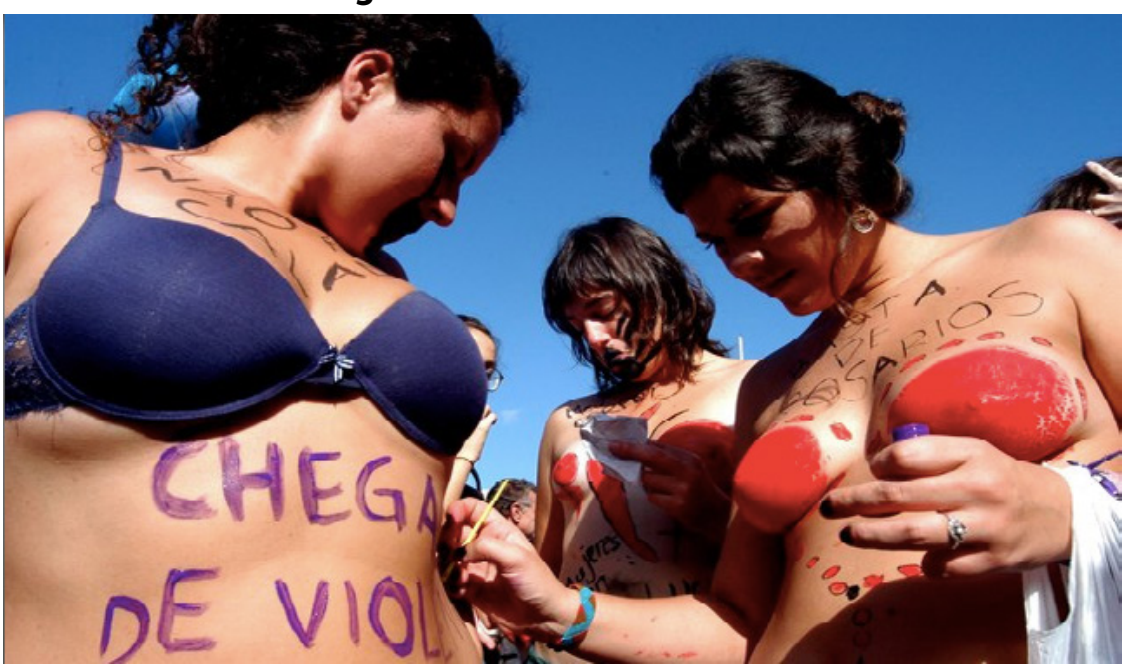

Fonte: https://bit.ly/3d2Hlhk. Acesso em: 20 ago. 2019. 
Figura 3. Marcha das Vadias

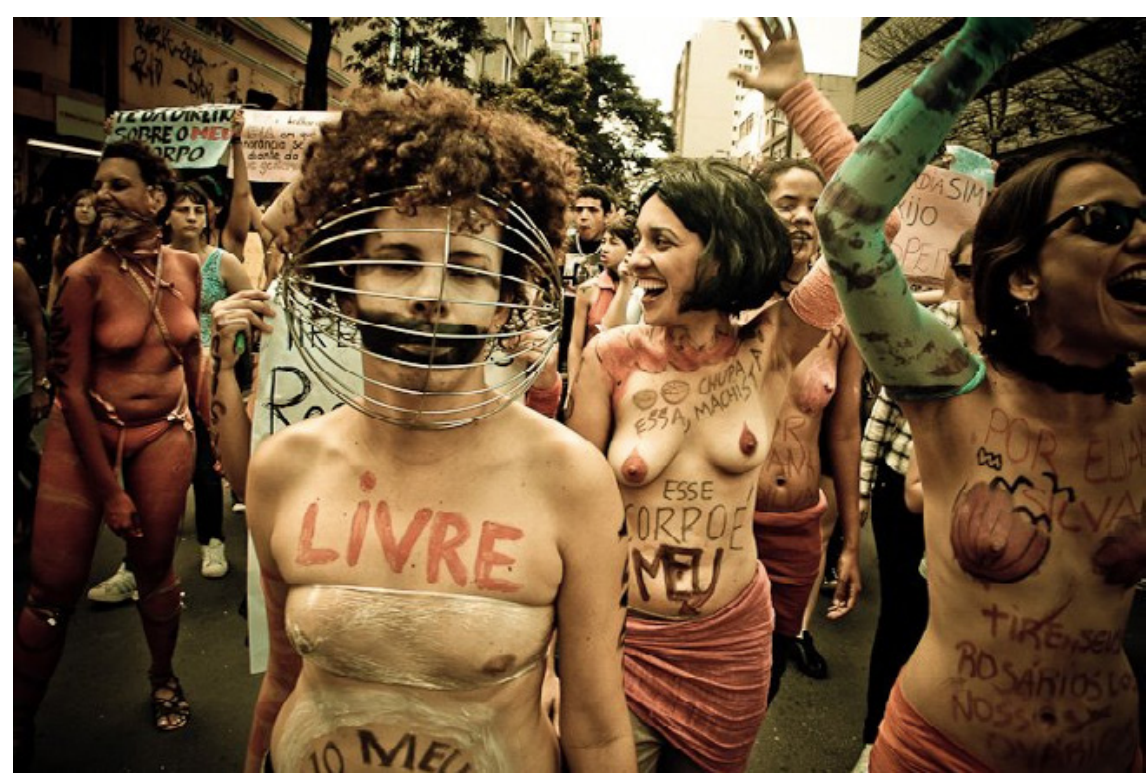

Fonte: https://bit.ly/2AcEPqe. Acesso em: 20 ago. 2019.

As três imagens representam metonimicamente uma parte da resistência empreendida pelas mulheres em diferentes protestos ocorridos durante a Marcha das vadias, em 2013, nas cidades do Rio de Janeiro (figura 2) e Belo Horizonte (figuras 1 e 3). A Marcha foi um movimento feminista recente (2011-2013) que foi responsável por trazer à tona algumas das discussões e reflexões acerca do que é ser mulher na atualidade e o seu papel numa sociedade ainda baseada na desigualdade de gênero. Seu ponto inicial foi promovido a partir de uma fala infeliz, em janeiro de 2011, de um policial canadense, Michael Sanguinetti, durante uma palestra na Universidade de Toronto, recomendando que "as mulheres evitassem se vestir como putas para não serem vítimas de estupro". Em protesto pelas ruas canadenses, cerca de três mil mulheres saíram às ruas como forma de reação à fala do policial.

Do episódio canadense, esse movimento cresceu ao redor do mundo ganhando contornos bastante expressivos como movimento social de repúdio ao assédio e à violência doméstica que muitas mulheres, ainda hoje, sofrem dos maridos e companheiros. No Brasil, o movimento começou em 2011 em diversas cidades. Impulsionadas pela fala do policial, e sobretudo, pela história de violência que acomete milhares de mulheres, podemos dizer que há uma memória de arquivo e os efeitos de sentidos gerados não são presos apenas ao contexto de produção, mas reverberam uma certa memória.

O corpo sempre foi uma forma de expressão, uma forma de discurso das mulheres, da representação da feminilidade e do pudor na antiguidade para movimentos que os tomam como máquina discursiva, em que ratificam a história num corpo que fala. Podemos 
dizer que, nas imagens, os efeitos de sentidos gerados pela inscrição do discurso no corpo ressignificam a história de violência. Ou seja, o que antes era tido como sagrado, oculto e privado, pois exaltava-se a sua feminilidade, a sua condição feminina, vemos um corpo que não se cala diante do preconceito e do machismo. Como forma de resistência a um idealismo utópico, o corpo, nas novas formulações textuais, discursiviza por meio de expressões que retomam uma memória de arquivo e funciona como gatilho para a instauração de uma nova memória, a de luta e resistência a preceitos conservadores e autoritários.

Para esse movimento de força feminina, há a ressignificação da memória da palavra "vadia", como vemos na figura 1: "se lutar por igualdade é ser vadia, então eu sou vadia!". Esse vocábulo há muito tempo traduz um sentido pejorativo e negativo. Se observarmos a sua definição no dicionário, o termo refere-se a uma "mulher que se comporta de modo considerado devasso ou imoral"7. Se compararmos com o slogan de campanha da Marcha, temos, assim, uma inversão de memória, uma reatualização de sentidos, em que se lê "vadia" euforicamente, como um termo que representa, de fato, a luta, a militância de um conjunto de mulheres que querem igualdade. A forma de se pintar, de marcar sua militância no e pelo corpo, nesse momento da história, ratifica fatores que rompem uma memória do ser privado e ressignifica-o no meio do espaço público. A tinta, os gestos, a resistência são reflexos de toda a história de violência impregnadas numa memória social e, ao mesmo tempo, fonte do dizer e de liberdade ${ }^{8}$.

Segundo Romão (2011), o arquivo é um conjunto de montagem de memórias que funciona por meio de diferentes materialidades que, com o efeito de inteireza, inscritos num processo de interpelação ideológica, passa a conferir-lhes uma certa ilusão e idealismo de evidência dos sentidos. Ao pintar os corpos, exaltar uma memória de violência, as mulheres reinventam e ressignificam a sua condição de feminilidade a partir de um arquivo, isto é, a violência é ressignificada por uma memória de luta, de militância. A violência do corpo "terno" e "frágil" não é mais a violência que o corpo pintado transmite pelas vozes que ecoam resistência. É uma violência ressignificada pela prática da luta pela igualdade, o corpo pintado, sob a forma da violência das palavras, expressões e objetos não é mais do que a ideologia dominada, impondo e buscando o seu lugar, quebrando espelhos e estereótipos cristalizados e utopicamente idealizados socialmente. O corpo, materializado no e pelo discurso, é a "arma" de guerra, é o instrumento de discursivização que há tempos sofreu pela repressão e exclusão e, agora, luta para ser ouvido, mostrar sua voz e o seu espaço tal qual o homem ocupa.

7 Definição retirada do Dicionário Priberam. Disponível em: https://dicionario.priberam.org/vadia. Acesso em: 20 ago. 2019.

8 Um ponto importante de observação nesse episódio é olhar a própria constituição da definição do vocábulo nos dicionários. Caberia a nós, e a todos, a seguinte pergunta: por que as suas edições e reedições, durante o processo de formulação, mantêm tais termos em circulação priorizando certos sentidos e, sobretudo, certas memórias de violência? 
Na segunda imagem, vemos o corpo dizendo "chega de violência", um discurso que remonta a toda história de sofrimento e instaura um novo cenário, é voz do corpo silenciado na história pelo pudor, é o início da militância de mulheres que saem às ruas para lutar pelos seus direitos, que a violência no/do seu corpo, causada por discursos machistas, não condizem com a atual realidade feminista. Tais possibilidades de dizer só são possíveis porque há formulação de discursos que nos permitem ressignificar a memória de violência e emergir um novo acontecimento de linguagem, as condições de produção (ORLANDI, 2002) permitem que seja possível essa reatualização da memória a partir das novas produções discursivizadas no material digital.

Na figura 3, a imagem, em primeiro plano, choca com a forma de dizer do corpo que milita em prol de um objetivo em comum: a liberdade. Vemos, assim, mulheres que se deslocam de certos estigmas sociais e chocam com discursos não condizentes com sua condição feminina idealizada historicamente. O ideal de mulher recatada, do lar e impedida explode com discursos que as colocam como seres iguais aos homens, com os mesmos direitos sexuais, por exemplo. "Esse corpo é meu", uma frase estampada na barriga de uma das manifestantes representa a voz do corpo que fala em discurso numa prática social não utópica. É o momento de ressaltar todas as qualidades e todos os (d)efeitos das mulheres, assim como os dos homens sem distinções, afinal, apesar da condição feminina, as mulheres podem e devem ser livres para todos os seus prazeres. Vale enfatizar o quanto esse corpo feminino que há tempos sofreu calado, coberto por roupas, fonte do sagrado e (re)contado por meio de estereótipos toma espaço e desmistifica esse ser mulher, colocando o desejo, o prazer e o querer feminino acima de valores autoritários. A mulher pode e deve sentir prazer e desejo como ela bem quiser, romper com imaginários que as colocam no lugar privado.

Se observarmos outro movimento social feminista, a Marcha das Margaridas, ocorrida nos dias 13 e 14 de agosto de 2019 na cidade de Brasília, com mais de 100 mil trabalhadoras, podemos encontrar uma certa regularidade no discurso de resistência, o corpo. Trata-se de um movimento de luta que ocorre desde os anos $2000^{\circ}$, com mulheres trabalhadoras rurais do país. Teve início após a morte de Margarida Maria Alves, assassinada enquanto lutava pelos direitos dos trabalhadores no estado da Paraíba.

Na página da Marcha das Margaridas, no Facebook, por exemplo, vemos também imagens que retratam a luta de corpos em discurso que saem às ruas para requererem seus direitos e espaços sociais, além das imagens divulgadas pela mídia. Vejamos:

9 A primeira edição contou com mais de 20 mil trabalhadoras rurais, entre elas camponesas, pescadoras, indígenas, quilombolas, entre outras de todas as partes do país. 0 evento é realizado a cada três anos na cidade de Brasília. Entre os objetivos do movimento estão a luta pela igualdade de direitos, a melhoria de políticas públicas no campo e a violência contra a mulher. 
Figura 4. Marcha das Margaridas

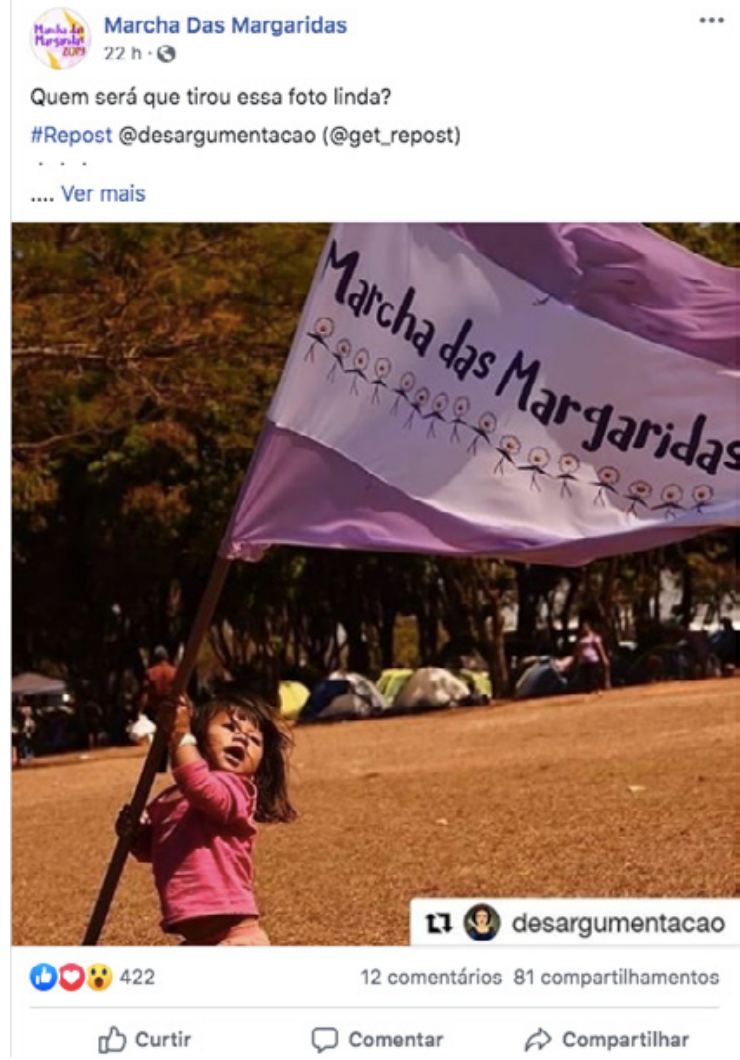

Fonte: https://pt-br.facebook.com/Marchadasmargaridas/. Acesso em: 20 ago. 2019.

Figura 5. Marcha das Margaridas

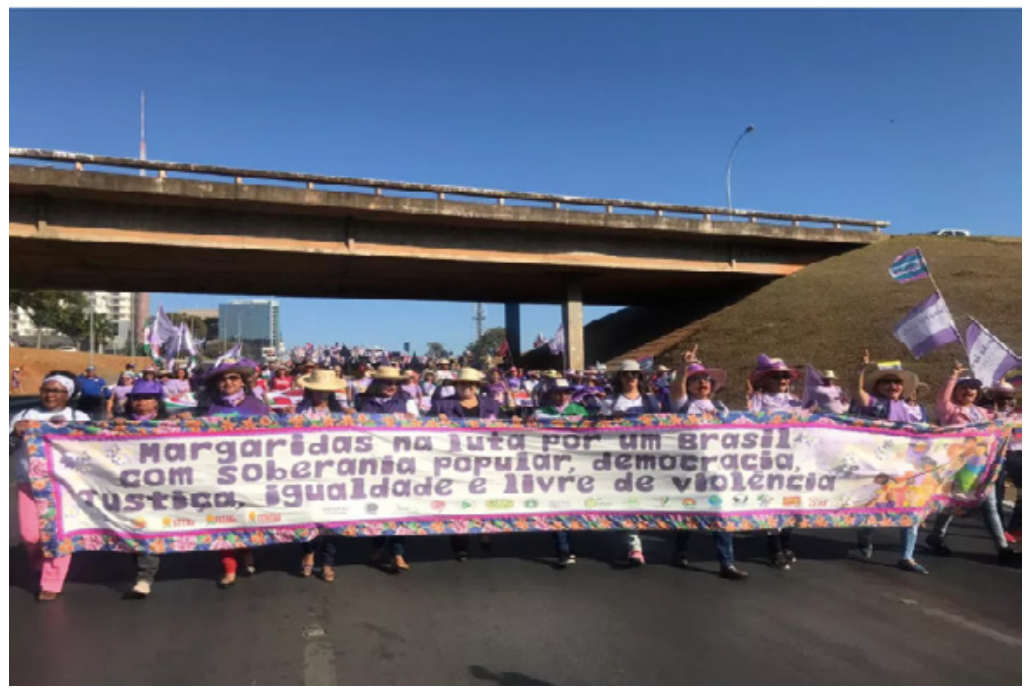

Fonte: https://glo.bo/2X46anE. Acesso em: 20 ago. 2019. 
Figura 6. Marcha das Margaridas

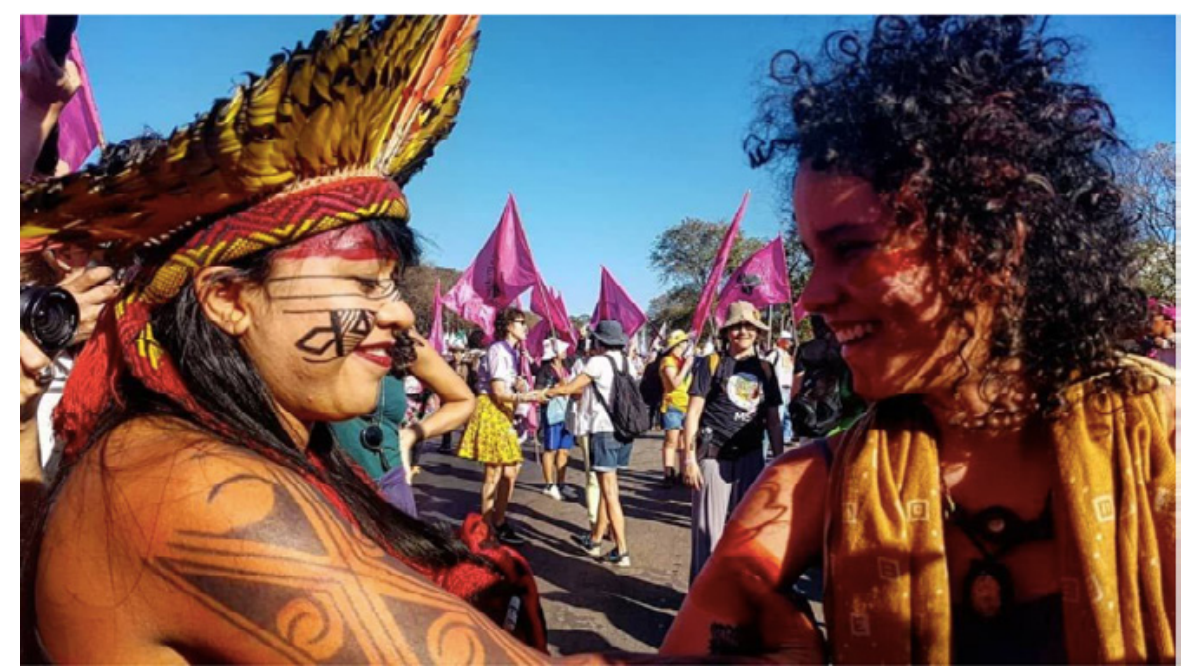

Fonte: https://bit.ly/2ZJGka6. Acesso em: 20 ago. 2019.

As imagens retomam uma regularidade importante desses movimentos sociais, o corpo como forma de expressão de liberdade e fonte de discurso. $O$ ato de sair às ruas, em busca dos ideais de liberdade, tornou-se, também, uma característica salutar para a instauração de uma nova memória social. O feminino saiu dos contornos privados e adquiriu novas instâncias de dizer, ocupou o espaço público no interior de um interdiscurso machista e preconceituoso.

Na figura 4, em sua página no Facebook, é possível dizermos que a criança levantando a bandeira do movimento representa metonimicamente a luta pela liberdade, o corpo criança, assim, traduz as lutas promovidas pelas novas gerações que já são tomadas pelos discursos de resistência e serão fundamentais para um futuro sem preconceito. Nesse sentido, é a representação da esperança de uma sociedade mais justa que levante a bandeira em prol de toda a nação, sem distinção de gênero. A partir de uma ideologia dominante, pré-construídos autoritários, a Marcha será resistência, por meio de várias gerações contra a violência às mulheres.

Na figura 5, a Marcha, que representa trabalhadoras rurais, camponesas, quilombolas, entre outras, ocupa espaços públicos como forma de ressaltar a voz do coletivo, de um conjunto de mulheres que acreditam e lutam pelos seus direitos. Os corpos em movimento ocupam o espaço social construindo novos ideais por meio de discursos de militância, fugindo de preconceitos e estigmas (im)postos. Trata-se de ir às ruas os corpos que entoam uma força de resistência que não se cala perante o machismo e o autoritarismo, desmistificando, desse modo, o lugar - público ou privado - que as mulheres ocupam. Por fim, a última imagem traduz a miscigenação de culturas que o 
nosso país representa e a força que todas juntas têm como forma de militar em prol de sua igualdade de direitos. Os corpos, na imagem, ocupam o lugar de fala de mulheres que não vão se calar diante da imposição de líderes autoritários. A pintura nos corpos, assim como na Marcha das Vadias, é o reflexo da luta contra a ideologia que prega o machismo, de um ideal feminino utópico, todavia, ao mesmo tempo, os corpos refratam também a militância, instaurando, desse modo, uma nova história marcada pela resistência. Marchar é colocar-se propositalmente a caminho de algum lugar, é, pois, mover-se do lugar comum, dos discursos dominantes e fascistas para a igualdade e democracia. É, pois, recontar a história de luta, instaurando uma nova memória e o corpo como objeto de resistência e ressignificação em prol de novas formações discursivas que desmistificam um já-dito cristalizado e estigmatizado.

\section{Considerações finais}

As mulheres, ao longo da história, sofreram elevados índices de violência psicológica, corporal e de feminicídios. Se observarmos do ponto de vista histórico, esses diferentes tipos de violência são herdeiros de uma cultura de base escravocrata que teve início a partir de um modelo colonizador que se instalou. Durante o auge das sociedades patriarcais, por exemplo, as mulheres foram privadas do convívio social para cuidar dos filhos e do casamento. O silêncio que as envolvia era impressionante, já que na História, diante da virilidade e da macheza idealizada e fortificada, tornaram-nas esquecidas. O ritual foi a prática do elevar o corpo ao campo sagrado, torná-lo sem voz, cujo único objetivo era a reprodução e objeto de desejo sexual. Embora fosse possível a representação do corpo feminino, o pudor e a opacidade de mostrá-lo em público tornavam-se uma heresia, pois ele pertencia ao seu senhor e sua feminilidade era considerada intocada aos olhos dos outros.

Aos poucos, a passos curtos, com o passar dos tempos, o processo de industrialização e a urbanização representou uma mudança radical na vida cotidiana das mulheres que passaram a assumir funções específicas que não mais as ligavam apenas ao "privado", ao conforto do lar, mas as tornaram livres, ligadas ao espaço "público", em que poderiam trabalhar nas ruas, estudar. Era preciso, pois, questionar certos valores patriarcais, dominados pelos homens, era o momento de as mulheres questionarem o machismo implementado e arraigado ao seu corpo silenciado por roupas longas e fechadas, pela privação ao ambiente familiar.

O corpo da mulher adquire um papel importante, o de fonte de discurso. O silenciamento já não condiz com a realidade; é preciso refletir sobre o novo cenário de construção discursiva acerca do seu papel na sociedade, adquirindo formas expressivas que o faz dizer. A modernidade foi responsável por propor novas práticas de leitura de um corpo que não se cala perante abusos e outras formas de violência. Surgiu a necessidade de as mulheres se imporem, se apropriarem delas mesmas e de lutarem pelo conhecimento 
e pela autonomia de seu corpo, umas das bandeiras do feminismo contemporâneo. É chegado o momento de revolucionar imaginários retrógrados e machistas e propor a fala de um corpo duramente violado ao longo da história. O corpo tornou-se discurso expresso por meio de diferentes dizeres que ressignificam o papel das mulheres nas sociedades atuais. Diante do material analisado, vemos como a memória assumiu contornos distintos, do corpo terno e delicado da história, das artes, da literatura à sua ressignificação no digital, possibilitando a emergência de uma nova memória de (r)existência que destaca as mulheres fortes em busca da sua liberdade e igualdade.

Diante disso, nesse breve percurso teórico-analítico, inscritos na análise do discurso de orientação francesa, nosso objetivo foi compreender essa nova memória de violência instaurada com os movimentos sociais brasileiros que resistem a certos imaginários machistas cristalizados na sociedade contemporânea em relação ao papel e ao lugar de fala da mulher. Além disso, observamos como a resistência das mulheres ecoou por meio do ciberespaço, como o seu corpo, tornado em discurso, redefine a memória histórica da mulher "privada" de direitos para uma mulher dona de si, livre. Em outras palavras, é possível analisar como essa nova memória criada pela militância ratifica um "avesso" na história tradicional, reposicionando a mulher numa outra instância discursiva, de mulher livre e dona de si.

\section{REFERÊNCIAS}

ALMEIDA, M. A. Memórias de um sargento de milícias. São Paulo: Ática, 1991.

AMADO, J. Tieta do Agreste. São Paulo: Companhia das Letras, 1977.

AZEVEDO, A. F. Sentidos do corpo: metáfora e interdiscurso. Linguagem em (Dis)curso, Tubarão, v. 14, n. 2, p. 321-335, maio/ago. 2014.

G1 DF. Trabalhadoras rurais fecham Eixo Monumental durante Marcha das Margaridas. 14 ago. 2019. Disponível em: https://glo.bo/2X46anE. Acesso em: 20 ago. 2019.

GARCIA, D. A. Efeitos de feminismo e mulher na marcha das vadias: a escrita do corpo. In: SCHERER, A.; SOUSA, L.; MEDEIROS, V.; PETRI, V. (org.). Efeitos da língua em discurso. São Carlos: Pedro \& João Editores, 2019.

IG São Paulo. Mulheres pintam os corpos e protestam no Rio. Grupos se concentram à tarde e à noite em Copacabana. 27 jul. 2013. Disponível em: https://bit.ly/3d2HIhk. Acesso em: 20 ago. 2019. 
LINHARES, J. Marcela Temer: bela, recatada, "do lar". Revista Veja, 18 abr. 2016.

Disponível em: https://bit.ly/3gswnUx. Acesso em: 6 maio 2020.

MALDIDIER, D. Michel Pêcheux: une tension passionnée entre la langue et l'histoire. In: MALDIDIER, D. Histoire et linguistique. Paris: Éditions de la Maison des Sciences de I'Homme, 1984.

MARCHA DAS MARGARIDAS. Marcha das Margaridas. Facebook, 2019. Disponível em: https://bit.ly/36xWcxK. Acesso em: 20 ago. 2019.

ORLANDI, E. P. Análise de Discurso: princípios e procedimentos. Campinas: Pontes, 2002.

OTTO, C. O Feminismo no Brasil: suas múltiplas faces. Revista Estudos Feministas, Florianópolis, v. 12, n. 2, p. 237-253, maio/ago. 2004.

PÊCHEUX, M. Papel da memória. In: ACHARD, P. (org.). Papel da memória. Campinas: Pontes, 2010.

PÊCHEUX, M. Semântica e discurso: uma crítica à afirmação do óbvio. Campinas: Unicamp, 2014.

PÊCHEUX, M.; FUCHS, C. Mises au point et perspectives à propôs de l'AAD. Langages, Didier/Larousse, Paris, n. 37, p. 51-68, 1975. [A propósito da Análise Automática do Discurso: atualização e perspectivas (1975). In: GADET, F.; HAK, T. (org.). Por uma análise automática do discurso. 5. ed. Campinas: Editora da UNICAMP, 2014.]

PINTO, C. R. J. Uma história do feminismo no Brasil. São Paulo: Fundação Perseu Abramo, 2003.

PORTAL SUL. BH: Marcha das Vadias acontece neste sábado. 2014. Disponível em: https://bit.ly/2AcEPqe. Acesso em: 20 ago. 2019.

ROMÃO, L. M. S. Exposições do Museu da Língua Portuguesa: arquivo e acontecimento e(m) discurso. São Carlos: Pedro \& João Editores, 2011.

SARAMAGO, J. As intermitências da morte. São Paulo: Companhia das Letras, 2005.

SARAMAGO, J. Ensaio sobre a cegueira. Lisboa: Caminho, 2001. 
SARAMAGO, J. Memorial do convento. Lisboa: Caminho, 2006.

SEMIRAMIS, C. Respondendo dúvidas sobre a Marcha das Vadias. Blogueiras feministas. 22 maio 2013. Disponível em: https://bit.ly/3c8LJdg. Acesso em: 20 ago. 2019.

VADIA. In: Dicionário da língua portuguesa. Priberam. Disponível em: https://dicionario. priberam.org/vadia. Acesso em: 20 ago. 2019.

VEJA. Bolsonaro zomba da esposa de Macron e é acusado de sexismo. 25 ago. 2019. Disponível em: https://bit.ly/3daJI1Q. Acesso em: 6 maio 2020.

VI O MUNDO. Marcha das margaridas: "combinaram de nos matar. E nós combinamos de não morrer". 14 ago. 2019. Disponível em: https://bit.ly/2ZJGka6. Acesso em: 20 ago. 2019 . 